Article

\title{
The LBP Gene and Its Association with Resistance to Aeromonas hydrophila in Tilapia
}

\author{
Gui Hong Fu ${ }^{1,2}$, Feng Liu ${ }^{1}$, Jun Hong Xia ${ }^{1,3}$ and Gen Hua Yue ${ }^{1,4,5, *}$
}

1 Molecular Population Genetics \& Breeding Group, Temasek Life Sciences Laboratory, 1 Research Link, National University of Singapore, Singapore 117604, Singapore;

E-Mails: snow03221@163.com (G.H.F.); liufeng@tll.org.sg (F.L.); xiajunh3@mail.sysu.edu.cn (J.H.X.)

2 Key Laboratory of East China Sea \& Oceanic Fishery Resources Exploitation and Utilization, Ministry of Agriculture of China, East China Sea Fisheries Research Institute, Chinese Academy of Fishery Science, Shanghai 200090, China

3 School of Life Sciences, Sun Yat-Sen University, Guangzhou 266061, China

4 Department of Biological Sciences, National University of Singapore, 14 Science Drive 4, Singapore 117543, Singapore

5 School of Biological Sciences, Nanyang Technological University, 60 Nanyang Drive, Singapore 637551, Singapore

* Author to whom correspondence should be addressed; E-Mail: genhua@tll.org.sg; Tel.: +65-6872-7405; Fax: +65-6872-7007.

External Editor: Helmut Segner

Received: 2 October 2014; in revised form: 17 November 2014 / Accepted: 24 November 2014 / Published: 1 December 2014

\begin{abstract}
Resistance to pathogens is important for the sustainability and profitability of food fish production. In immune-related genes, the lipopolysaccharide-binding protein $(L B P)$ gene is an important mediator of the inflammatory reaction. We analyzed the cDNA and genomic structure of the $L B P$ gene in tilapia. The full-length cDNA (1901 bp) of the gene contained a $1416 \mathrm{bp}$ open reading frame, encoding 471 amino acid residues. Its genomic sequence was $5577 \mathrm{bp}$, comprising 15 exons and 14 introns. Under normal conditions, the gene was constitutively expressed in all examined tissues. The highest expression was detected in intestine and kidney. We examined the responses of the gene to challenges with two bacterial pathogens Streptcoccus agalactiae and Aeromonas hydrophila. The gene was significantly upregulated in kidney and spleen post-infection with $S$. agalactiae and $A$. hydrophila, respectively. However, the expression profiles of the gene after the
\end{abstract}


challenge with the two pathogens were different. Furthermore, we identified three SNPs in the gene. There were significant associations $(p<0.05)$ of two of the three SNPs with the resistance to $A$. hydrophila, but not with the resistance to $S$. agalactiae or growth performance. These results suggest that the LBP gene is involved in the acute-phase immunologic response to the bacterial infections, and the responses to the two bacterial pathogens are different. The two SNPs associated with the resistance to A. hydrophila may be useful in the selection of tilapia resistant to A. hydrophila.

Keywords: tilapia; gene; SNP; pathogen; association

\section{Introduction}

Aquaculture is one of the major sources for the supply of animal proteins to humans. However, the success of aquaculture is impeded by the prevalence of infectious diseases [1]. Streptococcus agalactiae ( $S$. agalactiae) is a beta-hemolytic Gram-positive streptococcus. It is an emerging pathogen that has been associated with considerable morbidity and mortality in fish farms worldwide [2,3]. $S$. agalactiae infections were reported worldwide in a number of fish species, such as, seabream (Sparus auratus L.) [4], silver pomfret [2] and tilapia [5]. Besides S. agalactiae, A. hydrophila is a heterotrophic, Gram-negative, rod-shaped bacterium mainly found in areas with a warm climate. A. hydrophila is one of the causative agents of a serious haemorrhagic septicaemia that affects a wide range of freshwater fish, such as, zebrafish [6], crucian carp [7] and tilapia [8]. In recent years, the use of antibiotics has partially solved the problem of bacterial infections, but has raised concerns regarding antibiotic residues, environmental pollution and antibiotic resistance development. There is extensive interest in enhancing the resistance to diseases in aquaculture. However, increase of disease resistance through conventional breeding is very difficult. Marker-assisted selection (MAS) may greatly increase the efficiency and effectiveness for breeding compared to conventional breeding [9]. However, before MAS is feasible, markers tightly linked to disease resistance must be identified. Markers associated with disease resistance have been identified in salmon [10] and Japanese flounder [11], leading to substantial increase of disease resistance.

Single nucleotide polymorphism (SNP) markers are abundant and distributed widely and evenly throughout the genome [12]. SNPs serve as suitable markers for linkage mapping, and marker-assisted selection of important traits if they are closely linked to traits [9]. SNPs in the innate immune genes may play a role in determining susceptibility to a range of common diseases, which have an inflammatory component [13]. Previous studies showed that SNPs in some immune-related genes were associated with resistance against bacterial and viral pathogens in some fish species [14-17]. Thus, analysis of associations between SNPs in candidate genes and resistance against diseases may facilitate the genetic improvement of disease resistance.

Lipopolysaccharide binding protein (LBP) is a soluble acute-phase protein which plays an important role in lipopolysaccharide signaling and innate immunity [18,19]. The protein encoded by the $L B P$ gene is involved in the acute-phase immunologic response to gram-negative bacterial infections [20,21]. In fish, LBP also stimulates the non-specific and specific immune response. 
For example, LBP protected the immune response after immunization with Aeromonas hydrophila (A. hydrophila) in crucian carp [22], and also influenced the growth and immune stimulation in Atlantic salmon [23]. However, at present, limited information about whether the polymorphisms in the $L B P$ gene are associated with disease resistance is available in aquaculture species.

Tilapia is one of the most important good fish species in the world [24]. Its aquaculture faces the challenges of bacterial and viral diseases [24]. We have worked on developing molecular tools to facilitate the breeding of tilapia for growth and disease resistance $[17,25,26]$. The purposes of this study were to investigate the role of the $L B P$ gene in response to bacterial pathogen infections, and to examine whether SNPs in the gene were associated with the resistance to two major bacterial pathogens of tilapia: S. agalactiae and A. hydrophila. We identified the cDNA and genomic DNA sequence of the $L B P$ gene. We determined its expression profiles after challenge with the two pathogens at different time-points. We identified significant associations between the SNPs in the $L B P$ gene and the resistance to $A$. hydrophila, but not to $S$. agalactiae in tilapia. The SNPs associated with the resistance to $A$. hydrophila may be useful in the selection of tilapia resistant to A. hydrophila.

\section{Results}

\subsection{Sequence of $c D N A$ and Genomic DNA of the Lipopolysaccharide Binding Protein (LBP) Gene}

We identified the cDNA and genomic structure of the $L B P$ gene using bioinformatics tools and confirmed the sequences of the $L B P$ gene by PCR and sequencing PCR products. The full-length cDNA (1901 bp) of the LBP gene contained a 1416 bp open reading frame, encoding 471 amino acid residues. We also analyzed the genomic sequence of the LBP gene. It was $5577 \mathrm{bp}$, comprising 15 exons $(120,110,111,132,156,64,61,93,176,60,169,67,43,61$ and $78 \mathrm{bp}$, respectively) and fourteen introns (123, 124, 194, 757, 85, 127, 119, 183, 101, 1128, 224, 85, 86, 227 and $112 \mathrm{bp}$, respectively).

\subsection{Expression Profiles of the LBP Gene in Normal Individuals}

To determine the transcriptional level of the $L B P$ gene in various tissues of normal fish at the age of three months, qRT-PCR was performed. The expression levels of the gene in different tissues were compared with the level of expression in the brain (Figure 1). The LBP gene was constitutively expressed in all examined tissues. The highest mRNA expression was detected in the intestine, kidney and blood. The expression levels in liver and skin were moderate. The lowest mRNA expression was detected in the brain.

\subsection{Expression Profiles of the LBP Gene in Individuals Infected with Bacteria}

In order to understand the expression profiles of the $L B P$ gene after challenges with $S$. agalactiae and $A$. hydrophila, qRT-PCR analysis was used to examine the relative expressions of the $L B P$ gene in the liver, spleen, kidney and intestine (Figure 2). In the group challenged with S. agalactiae, the $L B P$ transcript increased up to 22.3 -fold at $48 \mathrm{~h}$ post-challenge, and decreased at other time-points compared to that of the control in the spleen. In the kidney, the LBP transcript increased 31.1-fold at $6 \mathrm{~h}$ post-challenge compared to the control group, and then was decreased from 12 to $48 \mathrm{~h}$. In the liver, the highest expression level increased 1.9-fold at $48 \mathrm{~h}$ post-challenge compared the control 
group. In the intestine, the $L B P$ transcript increased 5.0-fold at $1 \mathrm{~h}$ post challenge, and decreased at other time-points. The changes in expression of $L B P$ mRNA were also investigated after the challenge with $A$. hydrophila. The $L B P$ transcript level was induced significantly with a 32.8 -fold increase in the intestine $48 \mathrm{~h}$ post the challenge compared to the control group. The transcript level was induced significantly with a 35.1-fold increase in the kidney $6 \mathrm{~h}$ post the challenge in the kidney compared to the control group. However, in the liver and spleen, the transcription level was weakly induced compared to the intestine and kidney.

Figure 1. Expressions of the lipopolysaccharide binding protein $(L B P)$ gene in different tissues of normal tilapia. The relative expression fold- was calculated with the $\Delta \Delta C_{\mathrm{t}}$ method using $\beta$-actin as a reference gene. The expression in blood, kidney and intestine was significantly higher $(p<0.01)$ than in other tissues.

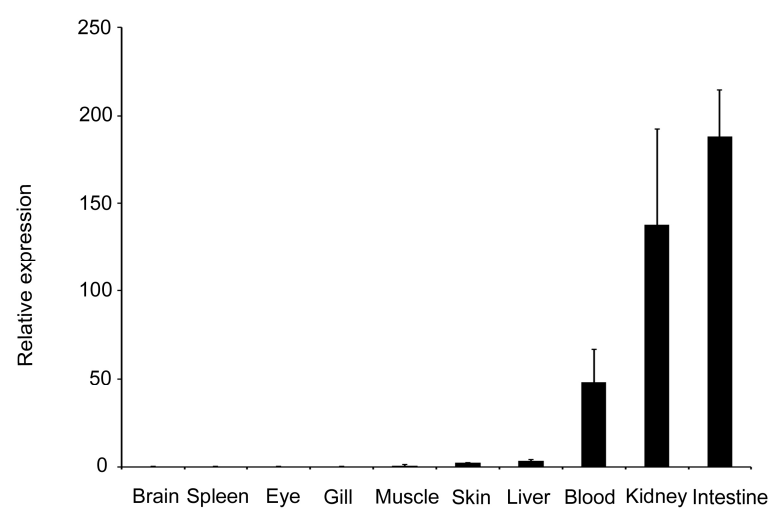

Figure 2. Expression levels of the $L B P$ gene in four tissues of tilapia after a challenge with bacterial pathogens $S$. agalactiae, and A. hydrophila, respectively. The relative expression after the challenge with bacterial pathogens $S$. agalactiae (A) and A. hydrophila (B), respectively was calculated with the $\Delta \Delta C_{\mathrm{t}}$ method using $\beta$-actin as a reference gene. The relative expression fold at each time point was compared to that of PBS-injected samples as control. $* *$ indicates that the expression was significantly $(p<0.01)$ higher than in other tissues.

(A)

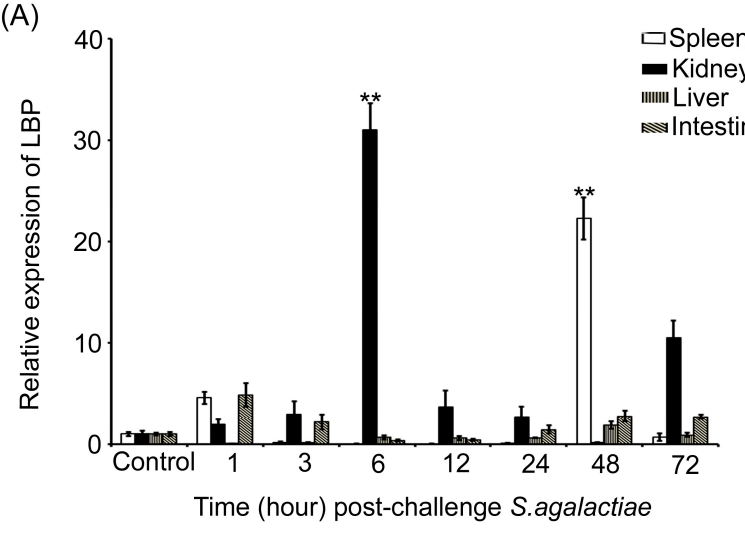

(B)

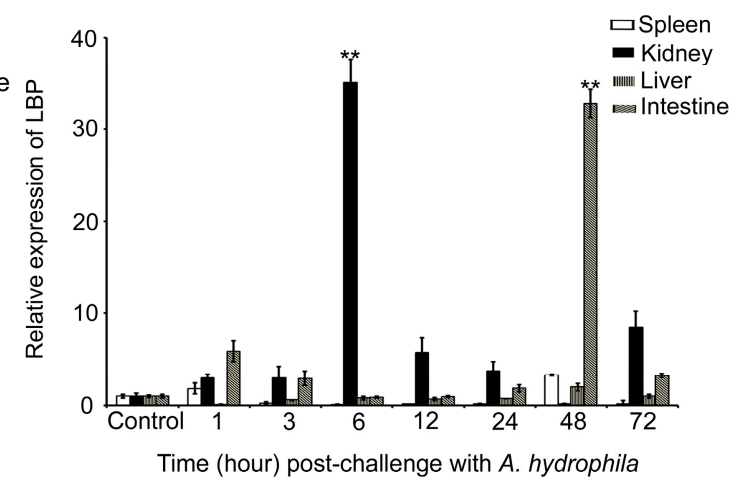

\subsection{Identification of Single Nucleotide Polymorphisms (SNPS) in the LBP Gene}

We identified three SNPs in the $L B P$ gene in 10 unrelated individuals by sequencing a part of the gene. One SNP (i.e., SNP3) was located in exon 6 and two SNPs (i.e., SNP1 and SNP2) were 
located in intron 5 of genomic DNA. The SNP1 g.1836 A>G and SNP2 g.1894 A $>$ G were located in intron 5. The SNP3 g.1948 G>C was located in exon 6, which resulted in an amino acid change (Figure 3).

Figure 3. Genomic structure of the $L B P$ gene and positions of known single nucleotide polymorphisms (SNPs) in tilapia.

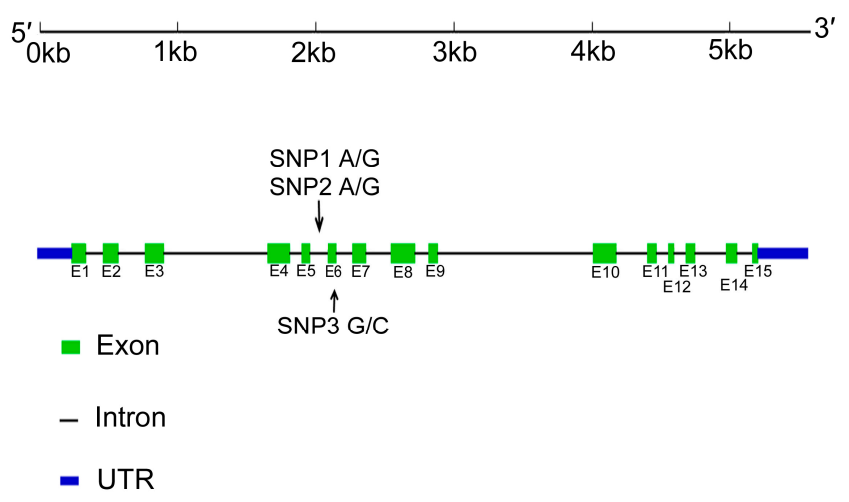

2.5. Identification of Associations between SNPS and Disease Resistance/Susceptibility to Bacteria in Tilapia

We found no significant association $(p>0.05)$ between all SNPs and the resistance to $S$. agalactiae disease. There were no significant differences $(p>0.05)$ in allele frequencies of the three SNPs in the surviving and dead fish (Table 1).

Significant associations $(p<0.005)$ between genotype distributions in SNP1 and SNP 3 of the $L B P$ gene and the resistance to the A. hydrophila were found (Table 1). However, there is no significant association $(p>0.05)$ of genotypes at SNP2 with the resistance to A. hydrophila (Table 1). We also analyzed the allele frequencies between the susceptible and resistant individuals. The results showed that SNP1 showed a significant association $(p<0.005)$ with the resistance to the A. hydrophila. In contrast, the allele frequencies at SNP2 and SNP3 were not significantly associated $(p>0.05)$ with the resistance to the $A$. hydrophila.

Table 1. SNPs in the $L B P$ gene in susceptible and resistant groups of tilapia.

\begin{tabular}{cccccccc}
\hline SNP & \multicolumn{3}{c}{ Number (\%) } & \multicolumn{5}{c}{ Allele Number (\%) } \\
\hline Genotypes & Susceptible & Resistant & $\boldsymbol{X}^{\mathbf{2}}$ & Allele & Susceptible & Resistant & $\boldsymbol{X}^{\mathbf{2}}$ \\
\hline S. agalactiae & & & & & & & \\
\hline SNP1 & & & & & & & \\
AA $(n=332)$ & $200(66)$ & $132(73)$ & 2.03 & A & $202(66)$ & $114(70)$ & 1.12 \\
AG $(n=150)$ & $102(34)$ & $48(27)$ & $(p>0.05)$ & G & $102(34)$ & $48(30)$ & $(p>0.05)$ \\
GG $(n=0)$ & $0(0)$ & $0(0)$ & & & & & \\
\hline SNP2 & & & & & & & \\
AA $(n=8)$ & $6(2)$ & $2(1)$ & 1.14 & A & $86(20)$ & $38(16)$ & 2.26 \\
AG $(n=58)$ & $40(13)$ & $18(10)$ & $(p>0.05)$ & G & $340(80)$ & $196(84)$ & $(p>0.05)$ \\
GG $(n=420)$ & $260(85)$ & $160(89)$ & & & & & \\
CC $(n=18)$ & $14(5)$ & $4(2)$ & 1.19 & C & $134(28)$ & $76(26)$ & 0.29 \\
\hline
\end{tabular}


Table 1. Cont.

\begin{tabular}{|c|c|c|c|c|c|c|c|}
\hline \multirow{2}{*}{$\frac{\text { SNP }}{\text { Genotypes }}$} & \multicolumn{3}{|c|}{ Number (\%) } & \multicolumn{4}{|c|}{ Allele Number (\%) } \\
\hline & Susceptible & Resistant & $X^{2}$ & Allele & Susceptible & Resistant & $X^{2}$ \\
\hline $\mathrm{CG}(n=96)$ & $60(20)$ & $36(20)$ & $(p>0.05)$ & G & $348(72)$ & $212(74)$ & $(p>0.05)$ \\
\hline $\mathrm{GG}(n=368)$ & $228(75)$ & $140(78)$ & & & & & \\
\hline \multicolumn{8}{|l|}{ A. hydrophila } \\
\hline \multicolumn{8}{|l|}{ SNP1 } \\
\hline $\mathrm{AA}(n=354)$ & $188(71)$ & $166(88)$ & 14.61 & A & 340 (69) & $206(82)$ & 20.70 \\
\hline $\mathrm{AG}(n=96)$ & $76(59)$ & $20(11)$ & $(p<0.005)$ & G & $152(31)$ & $44(18)$ & $(p<0.05)$ \\
\hline $\mathrm{GG}(n=2)$ & $0(0)$ & $2(1)$ & & & & & \\
\hline \multicolumn{8}{|l|}{ SNP2 } \\
\hline AA $(n=8)$ & $8(3)$ & $0(0)$ & 2.97 & A & $52(16)$ & $32(13)$ & 0.96 \\
\hline $\mathrm{AG}(n=38)$ & $22(8)$ & $16(8)$ & $(p>0.05)$ & G & $278(84)$ & $206(87)$ & $(p>0.05)$ \\
\hline $\mathrm{GG}(n=408)$ & $234(89)$ & $174(92)$ & & & & & \\
\hline \multicolumn{8}{|l|}{ SNP3 } \\
\hline $\mathrm{CC}(n=28)$ & $8(3)$ & $20(10)$ & 18.34 & $\mathrm{C}$ & $100(25)$ & $72(27)$ & 0.50 \\
\hline $\mathrm{CG}(n=72)$ & $46(18)$ & $26(14)$ & $(p<0.005)$ & G & $300(75)$ & $196(73)$ & $(p>0.05)$ \\
\hline $\mathrm{GG}(n=352)$ & $208(79)$ & $144(76)$ & & & & & \\
\hline
\end{tabular}

\subsection{Associations between SNPs in the LBP Gene and Growth Traits}

The three SNPs were found to be polymorphic in a family with 290 individuals where the growth traits of individuals were measured. The analysis of associations between the three SNPs and growth traits revealed that all three SNPs were not significantly $(p>0.05)$ associated with growth traits (Supplementary Table S1).

\subsection{In-Silico Mapping of the LPB Gene to Linkage Group 20}

Through in-silico mapping, the $L B P$ gene was mapped to linkage group 20 of the Nile tilapia genome. Around the location of the $L B P$ gene, the transporter genes, including vesicular inhibitory amino acid transporter, actin-related protein 5, protein slowmo homolog 2 and ATP synthase subunit epsilon, were also located.

\section{Discussion}

LBP is an acute-phase protein that initiates an immune response after recognition of bacterial LPS [18,19]. We cloned the full-length cDNA of the $L B P$ gene in tilapia. The gene encoded 471 amino acids, which is similar to the $L B P$ genes in other vertebrates [18,27-29]. The deduced amino acid sequence of the $L B P$ gene was highly homologous with that reported for fish, rat and human $L B P[27,30,31]$. The $L B P$ gene consisted of 15 exons separated by two relatively large introns $(0.8-1.1 \mathrm{~kb})$ and twelve small introns $(0.13-0.23 \mathrm{~kb})$. Comparison of the genomic DNA structure of $L B P$ from tilapia with those from other animals $[27,32,33]$ indicates that the $L B P$ gene has largely maintained its genomic structure during evolution. 
We investigated the expression profiles of the $L B P$ gene in normal fish at the age of three months using qRT-PCR. The LBP gene was expressed in all 10 tissues examined, and the highest expression was in the intestine and kidney. Similar expression patterns were reported in common carp [34], sweetfish Plecoglossus altivelis [29] and rock bream Oplegnathus fasciatus [28]. These results suggest that the LBP gene plays a wide range of roles in vertebrates. The kidney is an important immune organ in fish [35], and recent research showed that the intestine is also an important immune organ [36,37]. Therefore, the high expression levels of the $L B P$ gene in these two organs suggest that the $L B P$ gene plays an important role in the immune system in tilapia, which is in agreement with the findings in mammals [19,32].

We further analyzed the expression profiles of the $L B P$ gene in immune-related organs in fish challenged with $S$. agalactiae and A. hydrophila, which are the major pathogens that resulted in significant economic losses in aquaculture [38,39]. The expression levels of the $L B P$ gene were up-regulated in kidney, spleen, liver and intestine after challenge with $S$. agalactiae and A. hydrophila. The expression levels of the $L B P$ gene in $S$. agalactiae-infected fish were significantly increased in the kidney (up to 31.0-folds) and spleen (up to 22.0-folds) compared to the intestine (5.0-folds) and liver (1.9-folds). The expression levels of the $L B P$ gene in A. hydrophila-infected fish were increased in the kidney (35.1-folds) and intestine (32.8-folds) compared to the spleen and liver. Our results suggest that the $L P B$ gene is involved in the acute-phase immunologic response to bacterial infections. The different patterns of the expression profiles of the $L B P$ gene in fish challenged with two different bacterial pathogens indicate different responses of the gene to the two bacterial pathogens. A. hydrophila is a Gram-negative pathogen, which possesses a membrane component known as LPS. LBP is a specific protein that binds with LPS and is responsible for eliciting an immune response against LPS in vertebrates [34,40]. Therefore, the response of the LBP genes to the Gram-negative A. hydrophila is easily understandable. Certainly, it is also possible that the localization of these two bacteria in different tissues during infection could also be a reason for the different expression levels of the $L B P$ gene in different tissues infected with the two bacteria. However, in our study, we found that the $L B P$ gene also responded to the challenge of the Gram-positive bacterium $S$. agalactiae. S. agalactiae does not possess the LPS in its membrane. Therefore, the pathways involving the $L B P$ gene in response to Gram-positive and negative bacteria could be different. A previous study showed that $L B P$ also mediated cytokine induction caused by compounds derived from Gram-positive bacteria, including lipoteichoic acid and peptidoglycan fragments [41]. Further study on pathways involving the $L B P$ genes in fish may bring new insights on the functions of the $L B P$ gene in the resistance to bacterial pathogens.

We also examined whether the polymorphisms in the $L B P$ gene were associated with the resistance to the two bacterial pathogens $A$. hydrophila and $S$. agalactiae using association analysis. Three SNPs were detected in part of the $L B P$ gene. We detected significant associations in genotype distributions or allele frequencies of the SNP1 and SNP3 in the $L B P$ gene and the resistance to A. hydrophila. This result suggests that the $L B P$ gene itself plays a role in the resistance to $A$. hydrophila, or the $L B P$ gene is linked to a gene or several genes, which play a role in the resistance to A. hydrophila. However, with our current data, it is impossible to dissect these two possibilities. Using QTL mapping in segregating families, it is possible to know whether the associations were due to the $L B P$ gene itself or its linked genes. The $L B P$ gene was located in LG20, and DNA sequences flanking the $L P B$ gene are available 
in public domains (e.g., http://www.ensembl.org/Oreochromis_niloticus/Info/Index). Around the linkage location of the $L B P$ gene, there are transporter genes, including vesicular inhibitory amino acid transporter, actin-related protein 5, protein slowmo homolog 2 and ATP synthase subunit epsilon. It is easy to get DNA markers flanking the $L B P$ gene for QTL mapping. We noted that there was no association between SNPs in the $L B P$ gene and the resistance to $S$. agalactiae. This may be because $S$. agalactiae is a beta-hemolytic and heterotrophic Gram-positive streptococcus, while $A$. hydrophila is a heterotrophic, Gram-negative bacteria. Certainly, it is also possible that there are more than the three SNPs in the $L B P$ gene, and the use of three SNPs may not be able detect the association. Analysis of all SNPs in the $L B P$ gene may give more information about whether the $L B P$ gene is associated with the resistance to the Gram-positive bacterial pathogen $S$. agalactiae.

In conclusion, we identified and characterized the $L B P$ gene in tilapia for the first time. The $L B P$ gene was expressed in all tissues examined, but was highly expressed in the intestine and kidney. The different patterns of the expression profiles of the $L B P$ gene in the kidney, spleen, liver and intestine of fish challenged with two different bacterial pathogens (i.e., S. agalactiae and A. hydrophila) indicate different responses of the gene to the two pathogens. We found significant associations between two SNPs in the LBP gene and the resistance against A. hydrophila, but not against $S$. agalactiae. The two SNP markers associated with resistance against $A$. hydrophila may be used in the selection of fishes resistant to A. hydrophila.

\section{Experimental Section}

\subsection{Fish and Ethics Statement}

Tilapia individuals were cultured in a fish farm in Singapore. One hundred and fifty-two individuals at the age of 60-days post-hatch (dph) with an average body weight of $25 \pm 2.68 \mathrm{~g}$ were transported to a large tank containing $500 \mathrm{~L}$ seawater located in the animal house of our institute three weeks before the experiment. The fish were maintained in the large tank, and were fed twice daily with pellet feed (Biomar, Nersac, France). All handling of fish was conducted in accordance with the guidelines on the care and use of animals for scientific purposes set up by the Institutional Animal Care and Use Committee (IACUC) of Temasek Life Sciences Laboratory (TLL), Singapore. The IACUC of TLL has specially approved this study within the project "Breeding of tilapia resistant to microbe pathogens" in April 2012 (approval number: TLL (F)-12-004).

\subsection{Identification of $c D N A$ and Genomic DNA Sequences of the LBP Gene}

The cDNA sequence of the $L B P$ gene in tilapia was downloaded from NCBI database (DNA sequence Genbank No. XR_270272) and genomic DNA sequence was derived by BLAST the cDNA sequence against the assembled whole genome sequence of a Nile tilapia individual. The cDNA and genomic DNA sequences were used to design primers (Table 2) to confirm the cDNA and genomic DNA sequences, identify SNPs and analyze their expression levels in different tissues, respectively. 
Table 2. Primers used for amplifying genomic DNA of the $L B P$ gene, SNP identification and expression analysis in Mozambique tilapia.

\begin{tabular}{|c|c|c|c|c|}
\hline Name & Primer Sequence (5'-3') & $\mathbf{T}\left({ }^{\circ} \mathrm{C}\right)$ & Product Length (bp) & Application \\
\hline$L B P-R T-F 1$ & GGCGCAGCTGGGGAAAGAA & \multirow{2}{*}{60} & \multirow{2}{*}{269} & \multirow{2}{*}{ qRT-PCR } \\
\hline$L B P-R T-R 1$ & TGGGGACATCAGTGAGAGGAAGG & & & \\
\hline$\beta$-actin F1 & TGACCCAGATCATGTTCGAGAC & \multirow{2}{*}{60} & \multirow{2}{*}{253} & \multirow{2}{*}{ qRT-PCR } \\
\hline$\beta$-actin R1 & GTGGTGGTGAAGGAGTAGCC & & & \\
\hline$L B P-G-F 1$ & ACTTCTCAGTGACACAGGAAATTA & \multirow{2}{*}{57} & \multirow{2}{*}{1827} & \multirow{2}{*}{ Genomic DNA } \\
\hline$L B P-G-R 1$ & CTGGCTCCACCATGAAATTCTAT & & & \\
\hline$L B P-G-F 3$ & GAAAAGCAAAACCAACCAGCTTG & \multirow{2}{*}{57} & \multirow{2}{*}{2004} & \multirow{2}{*}{ Genomic DNA } \\
\hline$L B P-G-R 3$ & TATGACAGAAGTTGTTTTTAATCCT & & & \\
\hline$L B P-G-F 2$ & GGCGCAGCTGGGGAAAGAAGCTGA & \multirow{2}{*}{57} & \multirow{2}{*}{1902} & \multirow{2}{*}{ SNP detection } \\
\hline$L B P-G-R 2$ & TAGTTATAGGCATAGTATATGTTTG & & & \\
\hline
\end{tabular}

\subsection{RNA Extraction and Quantitative Real-Time RT-PCR}

Total RNA was isolated from five individuals at the age of two months using Trizol reagent (Invitrogen, Carlsbad, CA, USA) according to the manufacturer's instructions. Ten tissues were collected to examine expression profiles of the $L B P$ gene. These 10 tissues were the spleen, blood, brain, gill, intestine, liver, skin, kidney, muscle and eye. First strand cDNA was synthesized using Fermentas cDNA Synthesis Kit (Fermentas, Pittsburg, PA, USA) from total RNA (1.0 $\mu \mathrm{g})$. We used quantitative real-time PCR (qRT-PCR) with the primer pair LBP-RT-F1R1 (Table 2) to analyze the mRNA distribution in these samples. We used $\beta$-actin as the reference gene (Primers $\beta$-actin F1 and R1, Table 2). PCR amplification was performed in a total volume of $20 \mu \mathrm{L}$ containing 1× MaximaTM SYBR Green qPCR Master Mix (Fermentas, Pittsburg, PA, USA), $0.2 \mu \mathrm{L}(10 \mu \mathrm{M})$ of each primer and $1 \mu \mathrm{L}$ cDNA generated from RNA template. The cycling conditions consisted of an initial single cycle of $10 \mathrm{~min}$ at $95{ }^{\circ} \mathrm{C}$ followed by 40 cycles of $15 \mathrm{~s}$ at $95{ }^{\circ} \mathrm{C}, 30 \mathrm{~s}$ at $57{ }^{\circ} \mathrm{C}$ and $20 \mathrm{~s}$ at $72{ }^{\circ} \mathrm{C}$. PCRs were performed in triplicates. The transcription level of the $L B P$ gene was analyzed using the $\Delta \Delta C_{\mathrm{t}}$ method [42].

\subsection{Bacterial Challenge and Sampling Tissues}

Streptococcus agalactiae strain $\mathrm{ATCC}^{\circledR} 624^{\mathrm{TM}}$. The bacterial culture was grown for $24 \mathrm{~h}$ in Brain-heart infusion broth (BHI, Oxoid, UK) at $37{ }^{\circ} \mathrm{C}$ with continual shaking. The concentration of incubated bacteria was $1.0 \times 10^{8} \mathrm{CFU} / \mathrm{mL}$. Aeromonas hydrophila strain used was ATCC ${ }^{\circledR} 7966^{\mathrm{TM}}$. The bacterial culture was grown for $24 \mathrm{~h}$ in Trypticase soy broth (BHI, Oxoid, UK) at $30{ }^{\circ} \mathrm{C}$ with continual shaking. The concentration of incubated bacteria determined by standard direct plate count was $1.0 \times 10^{8} \mathrm{CFU} / \mathrm{mL}$. The bacteria for experiment were washed with PBS before injection to tilapia.

One hundred and five disease-free fish weighing $25.0 \pm 0.20 \mathrm{~g}$ were used in the bacterial infection experiment. Fish were divided into three groups (35 individuals in each group). The conditions were the same among tanks, and the fish were randomly distributed into different tanks. Three groups were cultured in three big tanks. Since our pretest showed that LD50 values of tilapia infected with S. agalactiae and A. hydrophila were $1.0 \times 10^{6} \mathrm{CFU} / \mathrm{mL}$, the first group received individual 
intraperitoneal injection with $0.1 \mathrm{~mL}$ of $S$. agalactiae of $1.0 \times 10^{6} \mathrm{CFU} / \mathrm{mL}$. The second group received intraperitoneal injection with $0.1 \mathrm{~mL}$ of $A$. hydrophila of $1.0 \times 10^{6} \mathrm{CFU} / \mathrm{mL}$. The third group injected just with PBS served as control. Sampling was performed 1, 3, 6, 12, 24, 48 and $72 \mathrm{~h}$ after challenge, with five fish in each group. Liver, spleen, kidney and intestine were sampled and kept in liquid nitrogen for total RNA extraction.

To analyze whether SNPs in the $L B P$ gene were associated with the resistance to the infections of the two bacterial pathogens, nine hundred and forty two disease-free tilapia individuals (weighing $25.8 \pm 0.8 \mathrm{~g}$ ) were used in this experiment. Fish were divided into two groups. Since the challenge with bacterial pathogens by immersion reflects natural infection, one group of tilapia was challenged with $S$. agalactiae while the other group was challenged with $A$. hydrophila by immersion exposure with approximately $10^{5}$ viable bacteria $\mathrm{mL}^{-1}$ tank water for $2 \mathrm{~h}$. Dissolved oxygen levels $(>5.7 \mathrm{mg} / \mathrm{L})$ were maintained throughout the exposure procedure. After an exposure period of $2 \mathrm{~h}$, the fish were removed and placed into their respective tanks and maintained at $28{ }^{\circ} \mathrm{C}$ in fresh water. All the fish were observed daily to survey the mortality, and samples were collected until the termination of the experiment at 14-days after challenge. Tilapia that died in the first $72 \mathrm{~h}$ post-challenge were classified into the susceptible group for their high sensitivity to bacteria, while the fish that survived over 14-days post-challenge were considered as a resistant group. Fin clips of each fish were collected for DNA extraction. DNA was isolated using a method developed by us [43].

\subsection{Identification and Genotyping of SNPs in the LBP Gene}

To identify SNPs in the $L B P$ gene, one pair of primers ( $L B P-G-F 2$ and $R 2$, Table 2$)$ were designed to amplify a part of the genomic DNA of the tilapia $L P B$ gene using PrimerSelect (DNAstar, Madison, WI, USA). PCR was conducted as described above. The genotyping of three identified SNPs were conducted by directly sequencing PCR products using an ABI 3730xl sequencer (ABI, Foster City, CA, USA). SNP genotypes were analyzed using the software Sequencher (Genecodes, Ann, Arbor, MA, USA). The genotypes were used to examine whether they were associated with disease resistance.

\subsection{Association Analysis of SNPS with Resistance to the Infection of Two Bacterial Pathogens}

In order to examine whether the SNPs in the $L B P$ gene were associated with resistance to $S$. agalactiae and $A$. hydrophila disease, we genotyped the surviving and dead individuals after challenge with two bacterial strains, respectively. We collected fin clips from 306 and 266 individuals susceptible to $S$. agalactiae and A. hydrophila respectively. One hundred and eighty and 190 individuals resistant to the $S$. agalactiae and $A$. hydrophila respectively were used as controls. SNPs in the $L B P$ gene were genotyped in all 942 fish. The Statistical Program for Social Science (SPSS) (SPSS Inc., Chicago, IL, USA) version 1.0 was used for data analysis. The frequencies of genotypes and alleles were compared in the susceptible and resistant individuals collected from the infections by two bacterial pathogens using Chi-square test. 


\subsection{Association Analysis of SNPs in the LBP Gene with Growth Traits}

To analyze associations between growth traits and SNPs in the LBP gene, a population, including 270 tilapia individuals was used. All fish were raised in the fish facility of Temasek Life Sciences laboratory. Individuals were raised communally in big tanks and maintained on strict feeding regimes until $140 \mathrm{dph}$. Growth traits, including body weight, standard and total length data were measured at $140 \mathrm{dph}$. Fulton's condition factor K (KTL: condition factor K based on total length, and KSL: condition factor $\mathrm{K}$ based on standard length) was calculated based on body weight (BW), Total length (TL) and Standard length (SL). Fin clips were sampled from each individual, and stored in 100\% ethanol for subsequent DNA extraction with the method described previously [43]. All individuals were genotyped by PCR amplification and sequencing of the genomic DNA of the MCP-8 gene as described above. Allele frequency for all the SNPs was statistically assessed using the Haploview software package [44]. Association between MCP-8 SNPs and quantitative traits were analyzed with SPSS 19.0 program.

\subsection{Mapping the LBP Gene to the Genome of Tilapia}

To map the $L B P$ gene to the genome of tilapia, we blasted the ORF of the $L B P$ gene against the assembled Nile tilapia genome sequence in the public domain (http://www.ensembl.org/ Oreochromis_niloticus/blastview). The hit with the lowest E value was regarded as the position of the gene in the tilapia genome. The scaffold containing the $L B P$ gene was derived and scanned for genes located near the $L B P$ gene using web-based software GENSCAN.

\section{Supplementary Material}

Supplementary table can be found at http://www.mdpi.com/1422-0067/15/12/22028/s1.

\section{Acknowledgments}

This research is supported by the National Research Foundation, Prime Minister's Office, Singapore under its Competitive Research Program (CRP Award No. NRF-CRP002-001). We thank our colleague May Lee for English editing, and the aquaculture team of Temasek Life Sciences Laboratory for supplying us tilapia individuals for our experiments.

\section{Author Contributions}

Gen Hua Yue initiated and supervised the project. Gui Hong $\mathrm{Fu}$ designed the experiments, conducted experiments and data analysis and drafted the manuscript. Gui Hong Fu, Jun Hong Xia and Feng Liu conducted the experiments. Gen Hua Yue finalized the manuscript.

\section{Abbreviations}

LBP, lipopolysaccharide-binding protein; S. Agalactiae, Streptcoccus agalactiae; A. Hydrophila, Aeromonas hydrophila; SNP, Single nucleotide polymorphism; qRT-PCR, Quantitative real-time PCR. 


\section{Conflicts of Interest}

The authors declare no conflict of interest.

\section{References}

1. Austin, B.; Austin, D.; Munn, C. Bacterial fish pathogens: Disease in farmed and wild fish. Rev. Fish. Biol. Fish. 1995, 5, 123-124.

2. Duremdez, R.; Al-Marzouk, A.; Qasem, J.; Al-Harbi, A.; Gharabally, H. Isolation of Streptococcus agalactiae from cultured silver pomfret, Pampus argenteus (euphrasen), in kuwait. J. Fish Dis. 2004, 27, 307-310.

3. Mian, G.; Godoy, D.; Leal, C.; Yuhara, T.; Costa, G.; Figueiredo, H. Aspects of the natural history and virulence of $S$. agalactiae infection in nile tilapia. Vet. Microbiol. 2009, 136, 180-183.

4. Evans, J.; Klesius, P.; Gilbert, P.; Shoemaker, C.; Al Sarawi, M.; Landsberg, J.; Duremdez, R.; Al Marzouk, A.; Al Zenki, S. Characterization of $\beta$-haemolytic group b Streptococcus agalactiae in cultured seabream, Sparus auratus L., and wild mullet, liza klunzingeri (day), in kuwait. J. Fish Dis. 2002, 25, 505-513.

5. Zamri-Saad, M.; Amal, M.; Siti-Zahrah, A. Pathological changes in red tilapias (Oreochromis spp.) naturally infected by Streptococcus agalactiae. J. Comp. Pathol. 2010, 143, 227-229.

6. Rodriguez, I.; Novoa, B.; Figueras, A. Immune response of zebrafish (Danio rerio) against a newly isolated bacterial pathogen Aeromonas hydrophila. Fish Shellfish Immunol. 2008, 25, 239-249.

7. Li, A.; Yang, W.; Hu, J.; Wang, W.; Cai, T.; Wang, J. Optimization by orthogonal array design and humoral immunity of the bivalent vaccine against Aeromonas hydrophila and Vibrio fluvialis infection in crucian carp (Carassius auratus L.). Aquat. Res. 2006, 37, 813-820.

8. Ardó, L.; Yin, G.; Xu, P.; Váradi, L.; Szigeti, G.; Jeney, Z.; Jeney, G. Chinese herbs (Astragalus membranaceus and Lonicera japonica) and boron enhance the non-specific immune response of nile tilapia (Oreochromis niloticus) and resistance against Aeromonas hydrophila. Aquaculture 2008, 275, 26-33.

9. Yue, G.H. Recent advances of genome mapping and marker-assisted selection in aquaculture. Fish Fish. 2014, 15, 376-396.

10. Houston, R.D.; Haley, C.S.; Hamilton, A.; Guy, D.R.; Tinch, A.E.; Taggart, J.B.; McAndrew, B.J.; Bishop, S.C. Major quantitative trait loci affect resistance to infectious pancreatic necrosis in atlantic salmon (Salmo salar). Genetics 2008, 178, 1109-1115.

11. Fuji, K.; Hasegawa, O.; Honda, K.; Kumasaka, K.; Sakamoto, T.; Okamoto, N. Marker-assisted breeding of a lymphocystis disease-resistant Japanese flounder (Paralichthys olivaceus). Aquaculture 2007, 272, 291-295.

12. Vignal, A.; Milan, D.; SanCristobal, M.; Eggen, A. A review on SNP and other types of molecular markers and their use in animal genetics. Genet. Sel. Evol. 2002, 34, 275-306.

13. Lazarus, R.; Vercelli, D.; Palmer, L.J.; Klimecki, W.J.; Silverman, E.K.; Richter, B.; Riva, A.; Ramoni, M.; Martinez, F.D.; Weiss, S.T. Single nucleotide polymorphisms in innate immunity genes: Abundant variation and potential role in complex human disease. Immunol. Rev. 2002, 190, 9-25. 
14. Kongchum, P.; Sandel, E.; Lutzky, S.; Hallerman, E.M.; Hulata, G.; David, L.; Palti, Y. Association between IL-10a single nucleotide polymorphisms and resistance to cyprinid herpesvirus-3 infection in common carp (Cyprinus carpio). Aquaculture 2011, 315, 417-421.

15. Siva, V.S.; Yang, C.; Yang, J.; Wang, L.; Wang, L.; Zhou, Z.; Qiu, L.; Song, L. Association of lgbp gene polymorphism with disease susceptibility/resistance of zhikong scallop (Chlamys farreri) to Listonella anguillarum. Fish Shellfish Immunol. 2012, 32, 1117-1123.

16. Fu, G.H.; Bai, Z.Y.; Xia, J.H.; Liu, X.J.; Liu, F.; Wan, Z.Y.; Yue, G.H. Characterization of the LECT2 gene and its associations with resistance to the big belly disease in asian seabass. Fish Shellfish Immunol. 2014, 37, 131-138.

17. Fu, G.H.; Bai, Z.Y.; Xia, J.H.; Liu, F.; Liu, P.; Yue, G.H. Analysis of two lysozyme genes and antimicrobial functions of their recombinant proteins in Asian seabass. PLoS One 2013, 8, e79743.

18. Schumann, R.R.; Flaggs, G.; Gray, P.; Wright, S.; Mathison, J.; Tobias, P.; Ulevitch, R. Structure and function of lipopolysaccharide binding protein. Science 1990, 249, 1429-1431.

19. Weiss, J. Bactericidal/permeability-increasing protein (bpi) and lipopolysaccharide-binding protein (lbp): Structure, function and regulation in host defence against gram-negative bacteria. Biochem. Soc. Trans. 2003, 31, 785-790.

20. Raetz, C.R.; Whitfield, C. Lipopolysaccharide endotoxins. Ann. Rev. Biochem. 2002, 71, 635.

21. Watson, J.; Riblet, R. Genetic control of responses to bacterial lipopolysaccharides in mice. I. Evidence for a single gene that influences mitogenic and immunogenic respones to lipopolysaccharides. J. Exp. Med. 1974, 140, 1147-1161.

22. Baba, T.; Imamura, J.; Izawa, K.; Ikeda, K. Immune protection in carp, Cyprinus carpio L., after immunization with Aeromonas hydrophila crude lipopolysaccharide. J. Fish Dis. 1988, 11, 237-244.

23. Guttvik, A.; Paulsen, B.; Dalmo, R.A.; Espelid, S.; Lund, V.; Bøgwald, J. Oral administration of lipopolysaccharide to atlantic salmon (Salmo salar L.) fry. Uptake, distribution, influence on growth and immune stimulation. Aquaculture 2002, 214, 35-53.

24. El-Sayed, A.-F.M. Tilapia Culture; CABI: Oxford, UK, 2006.

25. Liu, F.; Sun, F.; Li, J.; Xia, J.H.; Lin, G.; Tu, R.J.; Yue, G.H. A microsatellite-based linkage map of salt tolerant tilapia (Oreochromis mossambicus $\times$ Oreochromis spp.) and mapping of sex-determining loci. BMC Genomics 2013, 14, 58.

26. Xia, J.H.; Lin, G.; He, X.; Liu, P.; Liu, F.; Sun, F.; Tu, R.; Yue, G.H. Whole genome scanning and association mapping identified a significant association between growth and a SNP in the IFABP-A gene of the asian seabass. BMC Genomics 2013, 14, 295.

27. Su, G.L.; Freeswick, P.D.; Geller, D.A.; Wang, Q.; Shapiro, R.A.; Wan, Y.-H.; Billiar, T.R.; Tweardy, D.J.; Simmons, R.L.; Wang, S.C. Molecular cloning, characterization, and tissue distribution of rat lipopolysaccharide binding protein. Evidence for extrahepatic expression. J. Immunol. 1994, 153, 743-752.

28. Kim, J.W.; Gerwick, L.; Park, C.I. Molecular identification and expression analysis of two distinct bpi/lbps (bactericidal permeability-increasing protein/lps-binding protein) from rock bream, Oplegnathus fasciatus. Fish Shellfish Immunol. 2012, 33, 75-84.

29. Lu, X.J.; Chu, C.Q.; Chen, Q.; Chen, J. A novel lipopolysaccharide-binding protein $(L B P)$ gene from sweetfish Plecoglossus altivelis: Molecular characterization and its role in the immune response of monocytes/macrophages. Fish Shellfish Immunol. 2014, 38, 111-118. 
30. Inagawa, H.; Honda, T.; Kohchi, C.; Nishizawa, T.; Yoshiura, Y.; Nakanishi, T.; Yokomizo, Y.; Soma, G.I. Cloning and characterization of the homolog of mammalian lipopolysaccharide-binding protein and bactericidal permeability-increasing protein in rainbow trout Oncorhynchus mykiss. J. Immunol. 2002, 168, 5638-5644.

31. Larrick, J.W.; Hirata, M.; Balint, R.F.; Lee, J.; Zhong, J.; Wright, S.C. Human cap18: A novel antimicrobial lipopolysaccharide-binding protein. Infect. Immun. 1995, 63, 1291-1297.

32. Hubacek, J.A.; Büchler, C.; Aslanidis, C.; Schmitz, G. The genomic organization of the genes for human lipopolysaccharide binding protein (LBP) and bactericidal permeability increasing protein (BPI) is highly conserved. Biochem. Biophys. Res. Commun. 1997, 236, 427-430.

33. Kirschning, C.J.; Au-Young, J.; Lamping, N.; Reuter, D.; Pfeil, D.; Seilhamer, J.J.; Schumann, R.R. Similar organization of the lipopolysaccharide-binding protein ( $L B P$ ) and phospholipid transfer protein (PLTP) genes suggests a common gene family of lipid-binding proteins. Genomics 1997, 46, 416-425.

34. Kono, T.; Sakai, M. Molecular cloning of a novel bactericidal permeability-increasing protein/lipopolysaccharide-binding protein (BPI/LBP) from common carp Cyprinus carpio L. and its expression. Mol. Immunol. 2003, 40, 269-278.

35. Press, C.M.; Evensen, Ø. The morphology of the immune system in teleost fishes. Fish Shellfish Immunol. 1999, 9, 309-318.

36. Insoft, R.M.; Sanderson, I.R.; Walker, W.A. Development of immune function in the intestine and its role in neonatal diseases. Pediatr. Clin. N. Am. 1996, 43, 551-571.

37. Uematsu, S.; Fujimoto, K. The innate immune system in the intestine. Microbiol. Immun. 2010, 54, 645-657.

38. Toranzo, A.E.; Magariños, B.; Romalde, J.L. A review of the main bacterial fish diseases in mariculture systems. Aquaculture 2005, 246, 37-61.

39. Woo, P.T.; Bruno, D.W. Fish Diseases and Disorders: Viral, Bacterial and Fungal Infections; CABI: Oxford, UK, 2011; Volume 3.

40. Klein, R.D.; Su, G.L.; Schmidt, C.; Aminlari, A.; Steinstraesser, L.; Alarcon, W.H.; Zhang, H.Y.; Wang, S.C. Lipopolysaccharide-binding potein acelerates and augments Escherichia coli phagocytosis by alveolar macrophages. J. Surg. Res. 2000, 94, 159-166.

41. Schröder, N.W.; Heine, H.; Alexander, C.; Manukyan, M.; Eckert, J.; Hamann, L.; Göbel, U.B.; Schumann, R.R. Lipopolysaccharide binding protein binds to triacylated and diacylated lipopeptides and mediates innate immune responses. J. Immunol. 2004, 173, 2683-2691.

42. Livak, K.J.; Schmittgen, T.D. Analysis of relative gene expression data using real-time quantitative per and the $2^{-\Delta \Delta C t}$ method. Methods 2001, 25, 402-408.

43. Yue, G.H.; Orban, L. A simple and affordable method for high-throughput DNA extraction from animal tissues for polymerase chain reaction. Electrophoresis 2005, 26, 3081-3083.

44. Barrett, J.C. Haploview: Visualization and analysis of SNP genotype data. Cold Spring Harb. Protoc. 2009, doi:10.1101/pdb.ip71.

(C) 2014 by the authors; licensee MDPI, Basel, Switzerland. This article is an open access article distributed under the terms and conditions of the Creative Commons Attribution license (http://creativecommons.org/licenses/by/4.0/). 